\title{
Abnormal hypothalamus and related brain regions in Prader-Willi Syndrome evaluated in vivo by Diffusion Tensor Imaging (DTI)
}

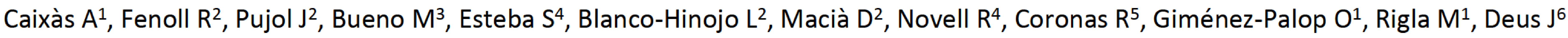

${ }^{1}$ Endocrinology and Nutrition Dpt, Corporació Sanitària Parc Taulí, Institut Recerca I3PT (UAB), Sabadell (Barcelona). ${ }^{2}$ MRI Research Unit, Hospital del Mar. CIBERSAM G21, Barcelona. ${ }^{3}$ Endocrinology and Nutrition Dpt, Hospital Arnau de Vilanova, Lleida. ${ }^{4}$ Mental Health and Intelectual Discapacity Specialized Department, Parc Hospitalari Martí $i$ Julià, Salt (Girona). ${ }^{5}$ Mental Health Department, Corporació Sanitària Parc Taulí, Institut Recerca I3PT (UAB), Sabadell (Barcelona). ${ }^{6}$ Department of Clinical and Health Psychology, UAB, Barcelona. All in Spain.
\end{abstract}

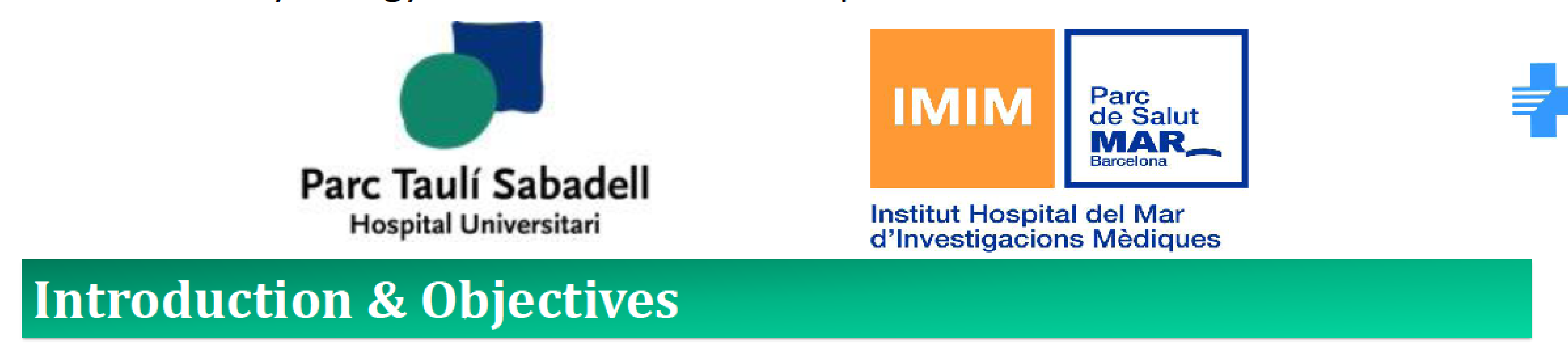

Prader-Willi syndrome (PWS) is a genetic disorder caused by the lack of expression of the paternally inherited genetic material located in 15q11-q13 ${ }^{1}$. It is characterized by neonatal hypotonia, intellectual disabilities, obesity and behavioral disturbance. Patients present with several neuroendocrinological abnormalities, such as growth hormone deficiency, hypogonadotropic hypogonadism, and hyperphagia, as the result of possible involvement of the hypothalamo-hypophyseal system².

Diffusion tensor imaging (DTI) provides information about structural properties of white matter. A commonly used DTI measurement is fractional anisotropry (FA), which serves to characterize white matter tracts by mapping the degree of water diffusion anisotropy (i.e., diffusion directionality) related to fiber density, axonal diameter and myelination degree.

To our knowlege there is only one study in PWS patients using DTI and it was not focused in the hypothalamo-hypopshyseal region ${ }^{3}$. So, the objective of the present study was to evaluate the hypothalamus and related brain regions in adult patients with PWS using DTI. nstitut Català de la Salu Hospital Universitarl Arnau de Vilanova

\section{UAB}

\section{Methods}

Twenty patients $(11 \mathrm{M}, 9 \mathrm{~F}$, aged $28.3 \pm 7.4)$ with PWS and twenty age- and gender-matched control subjects $(11 \mathrm{M}, 9 \mathrm{~F}$, aged $28.1 \pm 7.0)$ were recruited for this study. MRI data was acquired from all participants using a 1.5 Tesla Sigma Excite system (General Electric, Milwaukee, WI, USA). Diffusion-weighted scans were obtained using spin-echo single-shot echo-planar sequences of 25 directions with a B-factor of $1000 \mathrm{~s} / \mathrm{mm} 2$. Twenty-six slices were acquired with repetition time [TR] $8300 \mathrm{~ms}$; echo time $94 \mathrm{~ms}$; thickness $5 \mathrm{~mm}$, no gap; pulse angle $90^{\circ}$; field of view $26 \mathrm{~cm}$; $128 \times 128$ acquisition matrix reconstructed into a $256 \times 256$ matrix. The twenty-six slices were prescribed parallel to AC-PC line.

DTI images were preprocessed and Fractional Anisotropy (FA) maps were calculated using Functional MRI of the Brain (FMRIB) Software Library 5.0 (FSL). Data was re-sliced to a $1 \mathrm{~mm} \times 1 \mathrm{~mm} \times 1 \mathrm{~mm}$ anatomical resolution and normalized to standard $\mathrm{MNI}$ space. After, a smoothing $(8 \mathrm{~mm})$ was applied and voxel-wise two sample t-test was done between groups using SPM8.

Individual FA DTI maps were included in second-level (group) SPM analyses using 2-sample $t$-test. Results were considered significant with clusters of $1.032 \mathrm{ml}$ (1,032 voxels) at a height threshold of $p<0.005$, which satisfied the family-wise error (FWE) rate correction of $\mathrm{P}_{\mathrm{FWE}}<0.05$ according to Monte Carlo simulations.

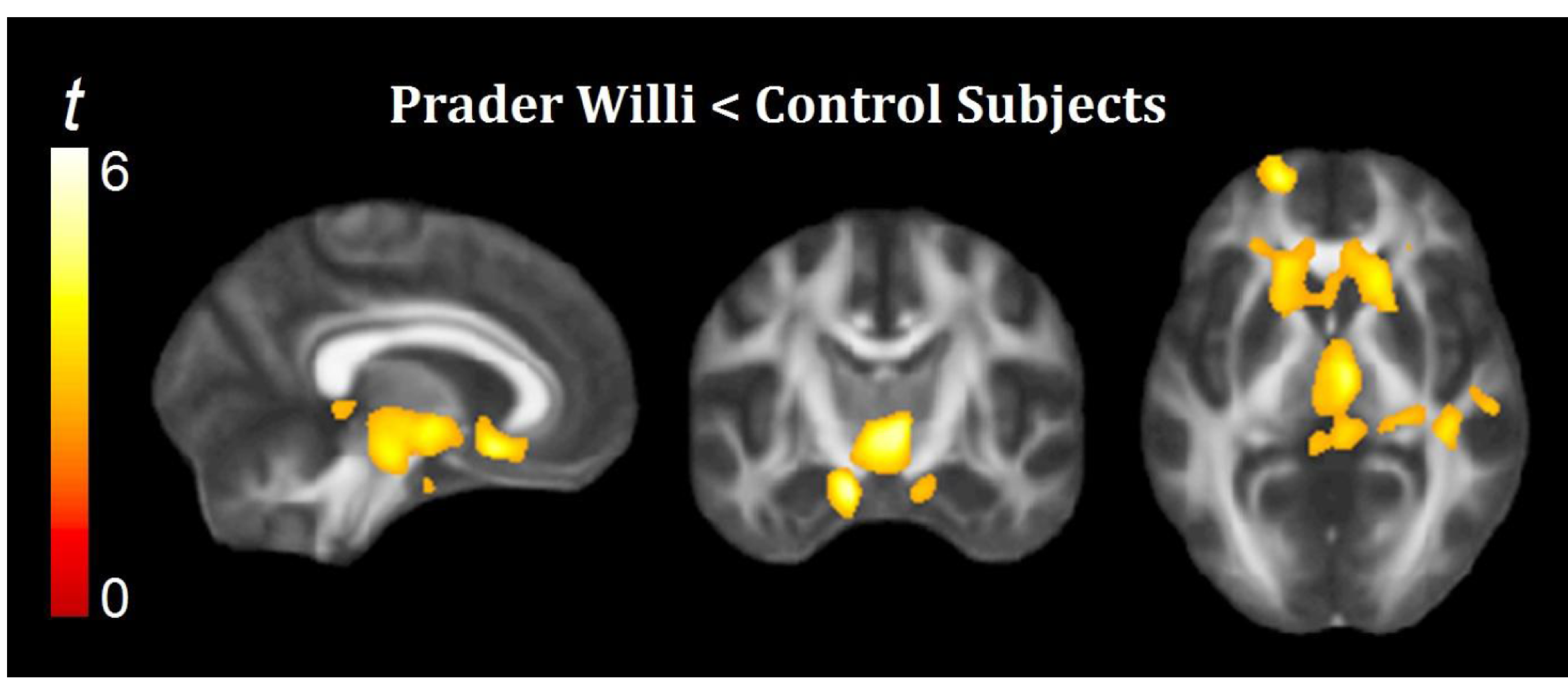

Table 1. Differences between groups.

\begin{tabular}{|c|c|c|c|}
\hline & $\begin{array}{l}\text { Cluster size, } \mathrm{ml} \\
\text { (voxels) }\end{array}$ & $\begin{array}{lll}x & y & z\end{array}$ & $T$ \\
\hline R Striatum & 799270 & $\begin{array}{lll}20 & 4 & -9\end{array}$ & 5.00 \\
\hline Striatum & 799270 & $\begin{array}{lll}-23 & 3 & -12\end{array}$ & 4.65 \\
\hline Hypothalamus & 799270 & $\begin{array}{lll}4 & -11 & -3\end{array}$ & 5.25 \\
\hline Amygdala & 799270 & $\begin{array}{lll}-12 & -8 & -21\end{array}$ & 5.61 \\
\hline Sub-Genu & 799270 & $\begin{array}{llll}-5 & 17 & -12\end{array}$ & 4.80 \\
\hline
\end{tabular}

$\mathrm{xy}$ z, coordinates given in Montreal Neurological Institute (MNI) space. Statistics at $p<0.005$.

Figure 1. Fractional Anisotropy (FA) differences between Prader-Willi patients and control subjects. FA is significantly reduced in the hypothalamus and anatomofunctionally connected structures such as the amygdala, the striatum and the subgenual part of the anterior cingulate cortex.

\section{Conclusions}

DTI results confirm the presence of extensive structural anomalies in white matter connecting the hypothalamus with related brain structures that may underlay endocrinological disorders and hyperphagia in these patients.

\section{References}

1 Cassidy SB, Schwartz S, Miller JL, Driscoll DJ. Prader-Willi syndrome. Genet Med. 2012 Jan;14(1):10-26. 2 Burman P, Ritzen EM, Lindgre AC. Endocrine dysfunction in Prader-Willi syndrome: a review with special reference to GH. Endocr Rev 2001; 22: 787-799.

${ }^{3}$ Yamada K, Matsuzawa H, Uchiyama M, Kwee IL, Nakada T. Pediatrics 2006; 118:e442-8 